\title{
Procedimentos para uma cena quase pronta: a vida de um mimo
}

Resumo: Neste Depoimento, o mímico Eduardo Coutinho conta os desafios profissionais e intelectuais que vivencia um mímico no Brasil de hoje e os caminhos que o levaram ao palco e à vida universitária, mostrando que a mímica pode ser também objeto de estudo e pesquisa. Neste percurso, mestres como Evreinov, Meyerhold, Étienne Decroux, Tomaszewski e Dario Fo nortearam sua postura enquanto ator e pesquisador e constituíram o arcabouço teórico da abordagem prática apresentada na tese que o tornou o primeiro doutor em Mímica do Brasil.

Palavras-chave: mímica, expressão corporal, arte, teatro, televisão.
Abstract: In this testimony, the mimic Eduardo Coutinho talks on the professional and intellectual challenges that a mimic lives nowadays in Brazil and the ways that took him to the stage and academic life, showing that mime can also be object of study and research. In this route, masters as Evreinov, Meyerhold, Étienne Decroux, Tomaszewski and Dario Fo, guided his posture as actor and researcher and built the theoretical framework used for the practical approach presented in the thesis that made him the first PhD in Mime in Brazil.

Keywords: Mime, body expression, art, theater, television

Sou mímico e, portanto, estou habituado a me expressar com o corpo e com os gestos. A linguagem verbal, tive que desenvolvê-la para falar aos meus alunos na sala de aula, e com os meus colegas. Mas sei da importância do texto escrito para registrar nossas idéias e transmitir nossos pensamentos até mesmo para aqueles que, como os leitores da revista Comunicação \& Educação, não estão aqui e agora ao meu lado para me ver e entender. Por isso, agradeço a oportunidade de dispor deste espaço para contar um pouco dos desafios profissionais e intelectuais que vivencia um mímico no Brasil de hoje. Gostaria também de me aproximar dos professores e educadores em geral para assegurar a importância da mímica, essa linguagem tão ancestral e, ao mesmo tempo, tão desvalorizada no mundo escolar e acadêmico. Meu Depoimento tem o objetivo de mostrar os caminhos tortuosos que me levaram ao palco e à vida universitária, mostrando que a mímica pode ser também objeto de estudo e pesquisa. Obrigado, honrado público, pela atenção que dispensarão a minhas palavras.

Por Eduardo Coutinho

Meus primeiros passos no teatro se deram em família, em meados da década de 1960. Quando minha avó, mãe de meu pai, ia nos visitar, era comum apresentarmos uma pequena peça de teatro nas escadas de minha casa em Bauru.

Mas a primeira vez que fui ao teatro profissional, por minha livre escolha, 
1. Ricardo Bandeira (19361992). Mímico, foi também poeta, escritor, dramaturgo, músico, compositor, produtor e diretor teatral. Conquistou três prêmios internacionais: na Finlândia, em 1962, na Bulgária, em 1968, e na Inglaterra, em 1970, com Hamlet, na própria cidade de Shakespeare, Stratfordupon - Avon. [N.E.]

2. Escola de Engenharia de São Carlos, da Universidade de São Paulo.

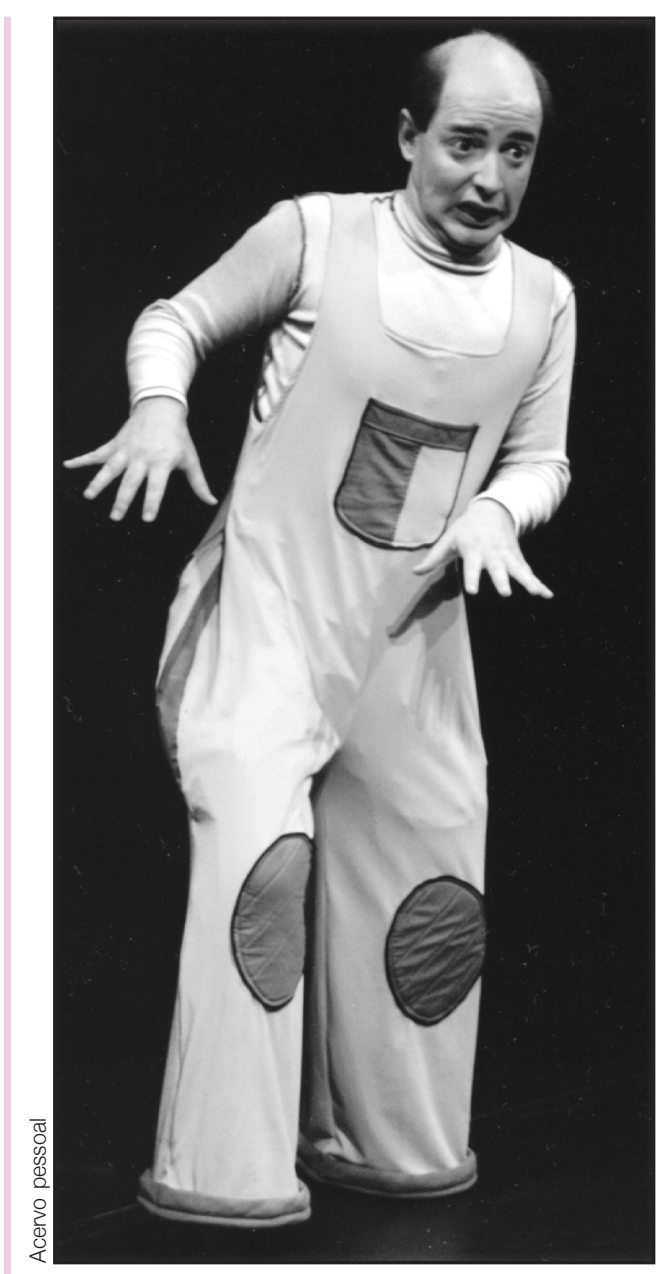

Eduardo Coutinho, o primeiro doutor em Mímica formado no Brasil. e Grande Otelo, em 1972. No final da peça, quando Dom Quixote morre, tive que disfarçar o choro.

A mímica já havia aparecido em minha vida em julho de 1970. Estava com 11 anos e passava as férias em um acantonamento, num tipo de hotel, chamado Acampamento dos Pumas, nos arredores de Campos do Jordão. Foram quatro semanas de atividades que nos ocupavam o dia todo - futebol, basquete, vôlei, remo, pesca, além de jogos de grupo e ateliê de artes. O monitor responsável era o Kim, um jovem ator formado pela EAD - Escola de Arte Dramática da ECA - Escola de Comunicações e Artes da USP - Universidade de São Paulo. Numa das noites, ele apresentou alguns quadros curtos de mímica, que havia aprendido. Fiquei fascinado com aquilo! No dia seguinte, o procurei para dizer que tivera uma idéia de um quadro que desejava que ele me ajudasse a realizar. Ele topou e ensaiamos duas vezes. Na noite seguinte, ao final da sua própria apresentação, Kim contou ao grupo que eu tinha preparado uma encenação. Essa foi minha primeira apresentação!

Após esta experiência, ao voltar a São Paulo, tentei entrar em contato com o mimo Ricardo Bandeira ${ }^{1}$, mas sem sucesso. O que ficou de concreto desse período foram as brincadeiras nas festas familiares e a demonstração para as visitas das aptidões artísticas do filho, que, no meu caso, eram uma pequena cena de mímica.

$\mathrm{Na}$ adolescência, as brincadeiras mudaram, a cena para as visitas acabaram e, por falta de estímulo, acabei por adiar a mímica para ser retomada em outro ponto de minha história.

\section{O REENCONTRO COM A MÍMICA}

Minhas outras aptidões vocacionais me levaram para a EESC-USP ${ }^{2}$, na área da engenharia civil, em 1977, mas, ainda no primeiro ano do curso, um episódio me aproximou novamente da mímica. De quantos imprevistos é feita nossa escolha profissional! Visitávamos um colega acidentado e, para aliviar o 
clima apreensivo que nos tomava, resolvi mostrar os quadros de mímica que havia aprendido com Kim e também os que eu tinha criado no acampamento do qual lhes falei. No grupo estava um veterano que, vendo minha tendência artística, me convidou para integrar o seu grupo de música. Em nosso primeiro ensaio ficou resolvido que eu não tocaria nem cantaria, mas mimaria as músicas do grupo. A escola tinha um show de quadros chamado Xou Vixe, um evento no qual os alunos de diversos cursos como Engenharia, Matemática e Física podiam mostrar os seus dotes artísticos tocando, cantando ou atuando.

Em 21 de outubro nos apresentamos no Xou. Meu grupo consentiu que eu contasse uma piada antes de começar nossa apresentação. Era a primeira vez que me apresentava diante de um público desconhecido de mais de 400 pessoas. Esta experiência positiva me deixou eufórico e me fez querer fazer mímica novamente.

\section{O PRIMEIRO CURSO DE MÍMICA}

No final do ano, quando voltei de férias para casa, meu pai surpreendeume com um recorte de jornal sobre um curso de mímica. Disse ele: "já que você diz que sabe fazer mímica, é melhor aprender!". Era um curso no Ballet Stagium que eu segui durante todo o mês de janeiro. Sotero, o professor, havia aprendido mímica com um mimo polonês, nos EUA.

Além dos primeiros passos na técnica da mímica, ele me ensinou o respeito à nossa arte; a necessidade de termos algo para dizer, a consciência de que palco não é apenas exibição e que a função do mimo é, antes de tudo, ética. Outra coisa importante que ele me disse foi para que eu deixasse de imitar mímica e começasse a fazer mímica. Esse é um segredo que deve servir para muitas outras profissões!

\section{COMO SER UM MIMO/ESTUDANTE DE ENGENHARIA?}

Na volta a São Carlos, em 1978, comecei a ter aulas de ballet clássico na Academia de Ballet Terpsícore. A proprietária, Dilma de Lima, havia dançado no importante Balé do IV Centenárioº ${ }^{3}$ Fiz um acordo com ela: eu teria as aulas de graça e, em contrapartida, dançaria todas as coreografias da escola. Até final de 1982, fiz também aulas de jazz, dança moderna e dança afro.

Aqui cabem algumas reflexões desta vivência com a dança: ela desenvolveu meu trabalho corporal, equilíbrio, minha força e consciência, e me mostrou a importância da repetição, do rigor da técnica, da precisão na execução da coreografia. Foi importante também a experiência de estar no palco apresentando uma arte na qual eu era muito limitado. Percebi, assim, que a presença cênica era fundamental.

Ainda em 1978, lembro-me de um fato que muito me marcou - fui procurado pela turma do quarto ano para ajudar em uma montagem teatral, com
3. Alusão às comemorações oficiais do quarto centenário de existência da cidade de São Paulo, em 9 de julho de 1954, para o qual o Balé foi especialmente organizado. [N.E.] 
comunicação \& educação • Ano XIII • Número 3 • set/dez 2008

uma cena de mímica. No dia da apresentação, entretanto, antes de iniciar minha parte, as luzes do centro acadêmico se apagaram. Chegamos a pensar em algum tipo de repressão, já que estávamos na época da ditadura e o movimento estudantil era ainda muito visado. Mas, rapidamente, apareceram muitas velas que, colocadas na frente do palco, criaram uma espécie de ribalta, permitindo que se continuasse o espetáculo. O público permaneceu e a emoção foi muito grande - a sensação era de que, com o teatro, vencíamos a repressão!

A mímica nesses anos de faculdade era minha menina-dos-olhos, apesar dos breves momentos de abandono. Apresentei quadros de mímica em todos os Xou Vixes entre 1977 e 1981, além de intervenções na praça da escola, em festas e em intervalos de jogos universitários. Em 1981, os alunos da escola participaram de

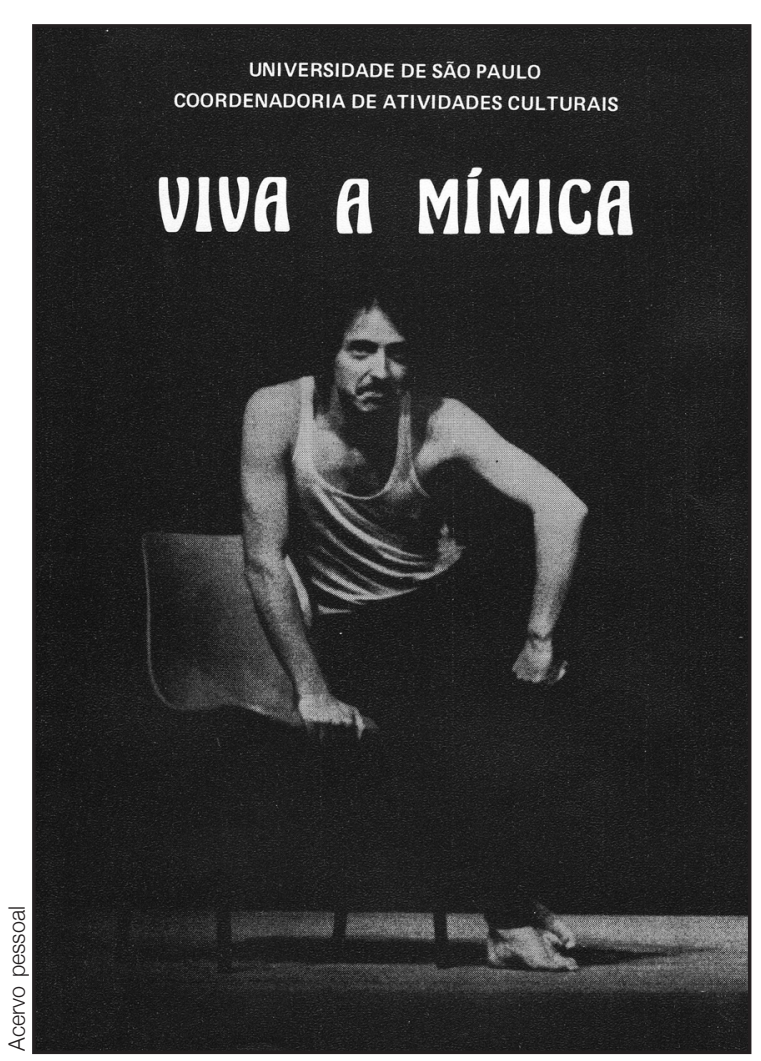

As primeiras experiências denotaram como a repetição, o rigor da técnica, a precisão na execução da coreografia e a presença cênica são fundamentais na atividade do mimo. um programa de competição de conhecimentos entre faculdades, apresentado pelo Walmor Chagas, chamado Quem sabe, sabe!, na TV Cultura (SP). A disputa foi EESCUSP contra a ECA-USP e uma das provas era a apresentação de um quadro de teatro. A ECA encenou uma cena narrada e ilustrada por alunos/atores. Nós apresentamos um quadro sobre futebol que eu criara.

Os jurados nos deram a vitória e, ao final do programa, Walmor Chagas perguntou-me sorrindo: "O que você está fazendo numa escola de engenharia?”. Fiquei perplexo! E felicíssimo! Não cabia em mim! Esta pergunta ajudou muito na minha decisão de assumir a mímica como profissão.

O período de faculdade de engenharia foi marcado por esta vida múltipla: estudante universitário, participação na área cultural do centro acadêmico, aulas e apresentações de ballet e mímica. Quanta dúvida e hesitação!

Por um lado, muitas parcerias, por outro, solidão. As atividades em São Carlos exigiam que eu ficasse na cidade também aos finais de semana. Os encontros com Sotero foram escasseando até que perdi o contato. Não tinha, portanto, um interlocutor para minhas questões em relação à mímica, uma pessoa com quem trocar idéias e aprender. Isso fez com que eu desenvolvesse uma disciplina muito particular de trabalho. Apesar da necessidade de momentos de trabalho solitário, criei um jeito de sempre integrar o trabalho de mímica ao cotidiano das outras 
atividades. Entretanto, este isolamento do meio teatral contribuiu muito para que eu me sentisse inseguro quanto à minha capacidade como artista.

\section{O PRIMEIRO ESPETÁCULO}

No início do meu sexto e último ano de faculdade, fui apresentado a um ator profissional chamado José Rosa, que trabalhava na época com Ronaldo Ciambroni. Ele me viu brincando com mímica e me perguntou se eu tinha quadros suficientes para compor um espetáculo. Despretensiosamente, disse que sim. Em 28 de maio de 1982, estreei no Teatro Municipal de São Carlos a peça "Viva a Mímica". Escrevi o programa com Agnaldo Arice Caldas Farias, meu professor de arquitetura na faculdade, hoje um importante crítico de arte e professor do Departamento de História da Faculdade de Arquitetura - FAU-USP. Fator de peso nesse espetáculo foi a presença da minha família e dos amigos mais próximos que fretaram um ônibus para ir a São Carlos me ver atuar, pela primeira vez, profissionalmente, num palco. Este reforço foi o empurrão que faltava para eu me decidir a assumir de vez a mímica.

Mas tive medo de que toda aquela excitação me impossibilitasse de terminar o curso que faltava muito pouco para ser concluído. E, para que o diploma não fosse comprometido, parei de fazer mímica e dança e fui estudar para me formar engenheiro. Nesse período de abstinência, acabei aceitando alguns desafios. O grupo de teatro da UFSCar fez um protesto no Parque Nacional de Sete Quedas, chamado Quarup de Sete Quedas, em repúdio ao fechamento das comportas de Itaipu e conseqüente extinção das cataratas. Fiz cenas de mímica sem preparo e sem os recursos necessários, mas consegui sucesso diante de cerca de 30 mil pessoas, público estimado pelos organizadores. Ao final, a platéia pediu bis! Eu fiquei completamente alterado com o inesperado sucesso! Era muita energia que vinha daquele mar de gente. Ao sair do palco, minha sensação era de que só o meu corpo havia descido. Não conseguia articular uma frase inteira, ver as pessoas felizes era o suficiente, não tinha capacidade de falar. Foi talvez a experiência mais intensa que vivi com a mímica. Tive a dimensão da alteração energética que um grande grupo de pessoas proporciona.

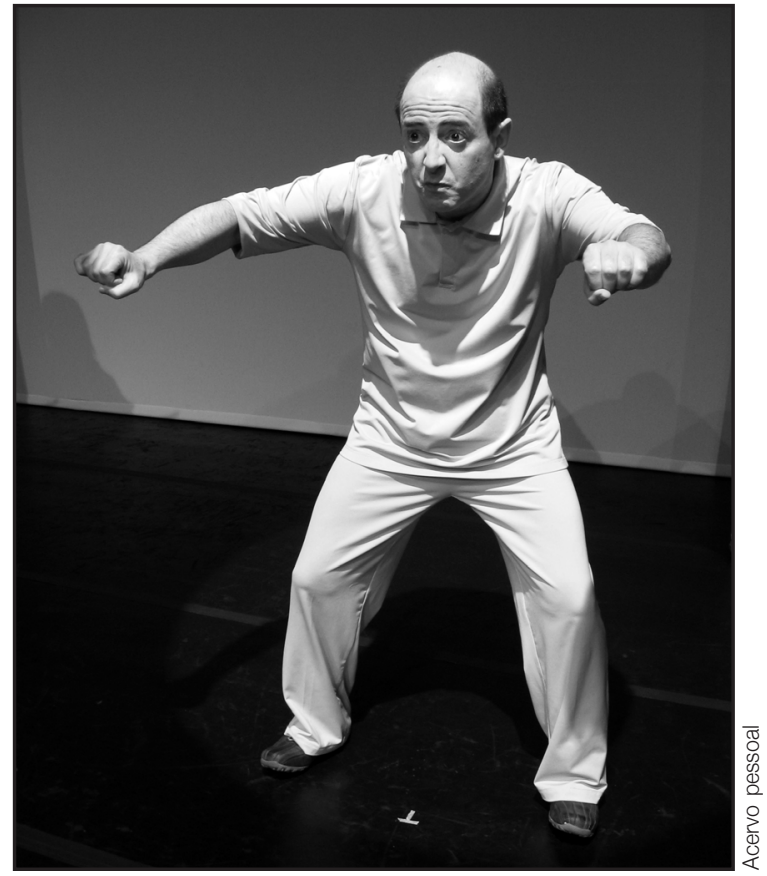

Experiências com a mímica: reação e emoção com a platéia. 
comunicação \& educação • Ano XIII • Número 3 • set/dez 2008

\section{BRASIL: CURSOS E PRIMEIRA TEMPORADA}

Em novembro, fui a São Paulo fazer um curso de mímica com Denise Stoklos, curso este que foi importante para toda uma geração de mimos brasileiros. Lá estavam Julio Sarkany, que foi assistente de Denise e hoje está radicado na Europa, Alice K., atualmente professora do Departamento de Artes Cênicas do Instituto de Artes da Unicamp, além de Eduardo Marquez, Eli Daruj, Gisela Arantes e Fábio Namatame, que formaram o Quadricrômico - Teatro Mímico. Junto com toda esta intensa experiência com o curso de mímica, vivenciei todos os ritos de formatura em engenharia, que para mim tinham um forte significado de despedida daquela etapa de vida.

Em 1983, fiz algumas apresentações em Araraquara, Ribeirão Preto e São Paulo, além de voltar a São Carlos. Também fiz performances em lugares diversos e atuei em comerciais de televisão como coadjuvante. Fábio Namatame me convidou para participar do espetáculo "Momentos" na Pinacoteca do Estado, com seu Grupo Porque Não, composto só de descendentes de japoneses, como ele. Fiquei feliz, pois foi a primeira vez que recebi um convite para atuar em um grupo de mímica. Fizemos uma bela apresentação!

Em outubro, apareceu em São Paulo um mimo chileno chamado Pato, Patrício Ossa, que ministrou um curso também no SESC Pompéia. Talvez mais importante do que a técnica que aprendi com Pato, foi perceber que deveria ampliar meu conhecimento sobre a mímica. Então resolvi deixar o país e ir para a Europa.

\section{NA EUROPA}

Parti em final de abril de 1984 para Roma. Algumas semanas depois, fui para Paris, onde cheguei em agosto. Lá, por orientação de Denise Namura, matriculei-me no Studio Magenia, da professora Ella Jaroszewicz ${ }^{4}$, polonesa e mima de Henryk Tomaszewski, e primeira esposa do mimo Marcel Marceau ${ }^{5}$. Para dedicar-me o máximo possível, fiz aulas extras à noite com o filho de Ella e de Marceau. Também consegui vaga para fazer um curso com o Théâtre $d u$ Mouvement, ministrado por Nelly Costecalde.

Esse período de Europa foi muito intenso e importante. Jamais esquecerei a sensação de estar em um lugar onde era apenas mais um mimo, um mero aluno, que poderia acertar e errar. E tinha também muitos colegas com quem

4. Disponível em <http:// www.magenia.com>.

5. Marcel Mangel, mais conhecido como Marcel Marceau ou Mime Marceau (1923-2007) foi o mímico mais popular de todo o mundo e o responsável em reviver esta arte no período pós-guerra. Atuou pelo mundo inteiro a fim espalhar a arte do silêncio (L'art du silence). [N.E.] podia trocar idéias e expor meus questionamentos, meus pensamentos e minha ignorância. Havia ainda o grande conhecimento prático adquirido no Studio Magenia, apesar do tempo reduzido que lá estive, a possibilidade de assistir a vários espetáculos de mímica, com diferentes propostas estéticas e a chance de conversar, discutir, trocar informações com colegas, professores e profissionais.

\section{DE VOLTA À REALIDADE BRASILEIRA}

Voltei ao Brasil perto do Natal de 1984 e, estimulado pelos colegas, comecei a ministrar cursos de mímica. Além disso, no segundo semestre de 1985, 
decidi fazer o trabalho de técnica vocal com Eudósia Acuña Quinteiro. Foi uma experiência individual, uma vez por semana, que durou até o final do ano seguinte. A busca pelo trabalho vocal já refletia minha visão sobre o mimo - acreditava que fazendo a voz parte do corpo, eu deveria trabalhá-la. Também retomei as apresentações de mímica, com espetáculos e, também, na televisão, como no programa Batalha 85, da TV Bandeirantes.

Em 1986 resolvi retomar um antigo projeto de dar aulas de mímica para professores da rede pública do Estado. Fui orientado a procurar a Profa. Dra. Hercília Tavares de Miranda, para quem comecei a expor minha idéia de oferecer o curso de mímica. De repente, um

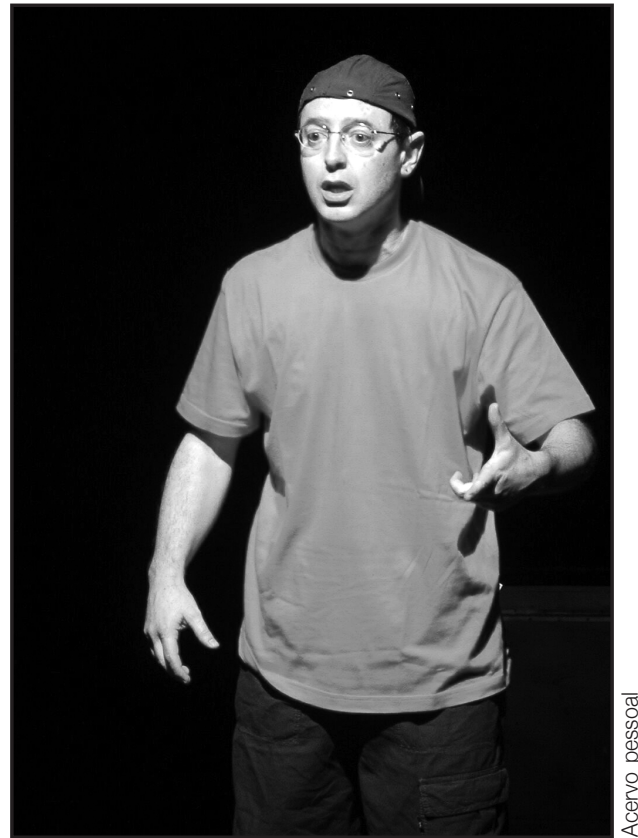

Dedicação e viagens para conhecer a técnica com mestres mimos: encontro entre iguais. professor de teatro, com quem Hercília dividia a aula, se aproximou e perguntou: "Eduardo Coutinho, certo?". Foi então que reconheci o Kim, monitor no Acampamento dos Pumas, aquele que me havia apresentado a mímica. Foi uma grande emoção!

Com um longo abraço, disse-lhe que ele era um dos responsáveis por eu estar ali. Ao assistir àquela cena, a professora Hercília disse: "Já sei do que você precisa. Você vai fazer pós-graduação na ECA!”. Assim conheci Clovis Garcia, responsável pela disciplina Técnicas Psicodramáticas Aplicadas ao Ensino I, que abriu um novo mundo para mim. Eu começava a refletir sobre minha prática artística.

Eudósia, colega na pós-graduação, me convidou para integrar um grupo de quatro professores para ministrar um curso de teatro na Fundação Cultural de São José dos Campos - SP, entre junho e dezembro. Fiquei com a área de expressão corporal. Foi o primeiro curso em parceria que ministrei, organizando meu conhecimento, que, associado aos demais, buscava atingir um determinado objetivo pedagógico - o de mostrar a importância do corpo nas relações entre as pessoas.

Eudósia também me convidou para fazer o trabalho corporal dos atores de uma peça de Carlos Alberto Soffredini, dirigida por ele mesmo. Este encontro com Soffredini foi muito importante pela sua postura profissional e pelo tempo que trabalhamos juntos - quase doze anos. Foi meu primeiro modelo de teatro de pesquisa não-acadêmica. $\mathrm{O}$ rigor na estética teatral e o respeito ao artista popular brasileiro eram as suas marcas. Soffredini me mostrou, no seu fazer teatral, que a pesquisa é parte integrante desta arte, que demanda estudo, mas que também exige um posicionamento político mais global, do artista como ser social.

Comecei este trabalho, que depois nomeei de direção corporal, em dezembro de 1986, utilizando-me da pouca experiência adquirida na montagem da peça 
comunicação \& educação • Ano XIII • Número 3 • set/dez 2008

"Na Carrera do Divino", que a essa altura estava sendo montada pelo Núcleo Estep - Núcleo de Estética Popular Teatral. Este trabalho foi o embrião da minha tese de doutorado. A estréia aconteceu em março de 1987. A experiência foi tão bem-sucedida que, em março, fui convidado por Neide Veneziano para preparar os atores de seu grupo, na cidade de Santos.

\section{A PESQUISA E A DOCÊNCIA}

Após ter tomado gosto pelo estudo do teatro, em final de 1987, estimulado por Clóvis Garcia, entrei para o Programa de Pós-Graduação em Artes, na área de Teatro, da ECA, sob sua orientação. Um pouco mais tarde, em 1989, fui aprovado para ser docente de Interpretação, na área de Mímica.

Aprendi que, além de artista, poderia ser um pesquisador e um professor capaz de multiplicar o número de mímicos ou daqueles que entendiam o que é (a) mímica.

Os anos seguintes foram intensos, anos de desenvolvimento dos papéis de pesquisador, de professor universitário e de artista (montei meu primeiro espetáculo em São Paulo). Aprendi outras coisas também - a ser companheiro e pai... Uni-me a minha esposa e tive meu primeiro filho, que nasceu em junho de 1989. Em 1990, iniciei a carreira de docente do Departamento de Artes Cênicas da ECA-USP.

A dissertação de mestrado, "O mimo e a mímica. Uma contribuição para a formação do ator brasileiro", demorou um pouco mais - foi aprovada pela banca no dia 24 de junho de 1993.

Mas, além da investigação científica e da pesquisa acadêmica, continuei sem cessar a educação de minha consciência corporal. Com Klauss Vianna e Karen Muller, busquei conhecer novas técnicas e aprimorar minha performance. Trabalhei em espetáculos com Soffredini, com o diretor Gabriel Villela, com Zeno Wilde e também com Silnei Siqueira. Meu trabalho artístico como mimo,

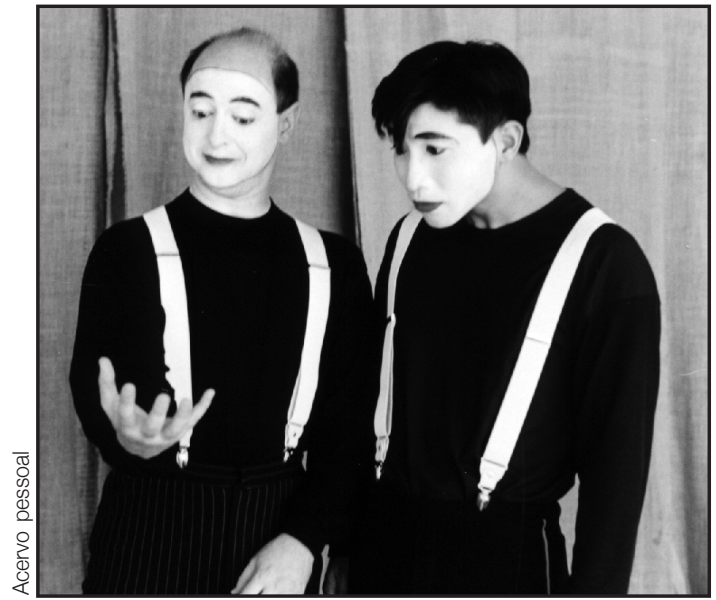

Com a pesquisa, Eduardo Coutinho experimentou a evolução e a interdisciplinaridade no aperfeiçoamento do fazer artístico. meu alimento indispensável, também se intensificou nesse período.

Nesse mesmo ano, 1993, aconteceram ainda dois fatos importantes. O primeiro foi poder criar e atuar no quadro "Mãos Pintadas", do programa Castelo Rá-tim-bum, da TV Cultura - SP. O segundo foi passar a atuar em um teatro baseado no Playback Theatre, que mescla apresentação teatral com direção de psicodrama. $\mathrm{O}$ diretor atua de maneira que a platéia, espontaneamente, conte histórias vivenciadas por ela. Ao término da fala do narrador, a 
história é encenada pelos atores do grupo. Esta técnica faz parte da minha prática profissional até hoje.

\section{A ETAPA DO DOUTORADO}

Em outubro de 1994, fui aprovado no exame de seleção para cursar o doutorado na Escola de Comunicações e Artes da USP. A tese "Uma cena precisa. Procedimentos para uma cena quase pronta", foi aprovada em 2000. Trata-se da organização de minha prática de quinze anos de pesquisa em direção corporal. Apresenta os procedimentos aplicados em ensaios na fase final de montagem de um espetáculo, a fim de que o ator fique mais consciente de suas ações e, conseqüentemente, possa atuar de forma mais precisa e segura. Os pensamentos de mestres como Evreinov, Meyerhold, Étienne Decroux, Tomaszewski e Dario Fo nortearam minha postura enquanto ator e pesquisador e constituíram o arcabouço teórico da abordagem prática apresentada na tese. Tornei-me o primeiro doutor em Mímica formado no Brasil.

Mais tarde ministrei aulas de "Mímica e a expressão corporal", dentro do curso "Introdução à abordagem Corporal para Profissionais de Saúde", promovido pelo Laboratório da personalidade, do Instituto de Psicologia da USP, para profissionais do serviço público estadual. Estive na Semana do Terapeuta Ocupacional da PUC - Campinas, ministrando uma vivência sobre "Mímica e a consciência corporal".

No trabalho com mímica, acabei encontrando outras formas ainda mais desafiadoras de atuação. Em 2000 fui indicado por uma ex-aluna do CAC - Departamento de Artes Cênicas da ECA-USP para desenvolver, com os educadores da CETED, da CET-SP, uma intervenção de educação no trânsito. A idéia era utilizar a técnica da mímica para educar os pedestres a utilizarem a faixa para atravessar as ruas. O resultado foi tão bom que este projeto existe até hoje.

Gravei, ainda, catorze esquetes de mímica para o programa X-TUDO, da TV Cultura - SP, que também gravava com outros mimos. A cada programa novo é utilizado apenas um dos esquetes gravados.

\section{ALGUMAS REFLEXÕES}

Ao escrever sobre as atividades como pesquisador, pude perceber uma evolução em cada fase na relação com o fazer artístico. No período do mestrado, o pesquisador e o artista eram separados, apesar da dissertação falar sobre mímica e trazer minhas reflexões sobre esta arte. No período do doutorado, o pesquisador acolhe o artista, fazendo com que a prática artística seja a base da pesquisa. Isto é, o pesquisador aprende com o artista. Atualmente, sinto que não há mais separação entre o pesquisador e o artista; os dois lados buscam os mesmos objetivos em parceria.

Sobre a docência, pude constatar alguns motivos para exercê-la. Primeiro o prazer de levar aos alunos minha paixão, isto é, a arte da mímica. Depois, a 
comunicação \& educação • Ano XIII • Número 3 • set/dez 2008

possibilidade de acompanhar o momento de transformação dos alunos, podendo agir de maneira pedagógica também fora do espaço didático da aula.

Todos os meus trabalhos são colaborativos e coletivos. Exercito permanentemente o exercício de dar voz aos alunos, mesmo que seu discurso se faça por meio do corpo e dos gestos. Há sempre a predominância do objetivo de dar lugar às mais diversas posições e idéias dos alunos. Mesmo que eu me coloque, procuro respeitar as diferenças e, em seguida, trabalharmos juntos sem restrições. Este é um treino de democracia, também da verdadeira arte.

\section{O FAZER ARTÍSTICO}

Para concluir este Depoimento, quero ressaltar que a mímica é uma linguagem difícil, como qualquer atividade artística que se leva a sério. (Muito mais difícil do que os conhecimentos de engenharia que eu, erroneamente, pensava poderem balizar minha vida profissional.) Mas, apesar de difícil, a mímica pode se tornar uma profissão e uma arte que seja o centro de uma vida, desde que estejamos dispostos a nos dedicar a ela de forma permanente, como devemos fazer em qualquer área na qual desejemos nos especializar. Como procurei relatar, não parei nunca de procurar e de me aproximar dos maiores artistas e diretores, dos melhores professores, para com eles aprender as técnicas mais difíceis.

Por outro lado, compreendi que a interdisciplinaridade é parte inerente de nosso aperfeiçoamento. Apliquei a mímica a diferentes campos de atuação, assim como soube misturá-la à educação, à psicologia e à política. Não bastava saber mímica, era preciso aprender mais, desenvolver parcerias e uma visão mais complexa do meu fazer artístico.

Finalmente, entendi que aquilo que eu sabia podia ser aprofundado através da pesquisa científica e da especulação filosófica e dediquei-me à vida acadêmica com a mesma intensidade de meus professores de engenharia, não havendo diferença quer no interesse, quer no esforço por buscar o melhor desempenho. Eu havia aprendido que nada é por acaso, nem acontece gratuitamente.

Esse foi o Depoimento no qual procurei registrar que a mímica é uma arte séria e maravilhosa, que resulta de intenso trabalho de aprofundamento na pesquisa artística e na reflexão teórica. Que nenhuma vocação se delineia sem a prática e a experiência, que necessitamos sempre de talento, assim como de bons mestres e de muito estímulo. Espero que, a partir desse esforço por falar por palavras em vez de gestos, meus leitores consigam ver com outros olhos a mímica. Gostaria de encerrar explicando que, mesmo aqueles que não são mímicos, devem tomar consciência da importância de seu corpo e de seus gestos, pois, somente assim, habitando conscientemente nosso corpo, teremos possibilidade de nos tornar pessoas plenas. Este é o principal ensinamento de um professor de mímica. 